\title{
Thunderstorm allergy and asthma: state of the art
}

\author{
Gennaro D'Amato, ${ }^{1,2}$ Isabella Annesi-Maesano, ${ }^{3,4}$ Marilyn Urrutia-Pereira, ${ }^{5}$ Stefano Del Giacco, ${ }^{6}$ Nelson A. Rosario \\ Filho, ${ }^{7}$ Herberto J. Chong-Neto, ${ }^{7}$ Dirceu Solé, ${ }^{8}$ Ignacio Ansotegui, ${ }^{9}$ Lorenzo Cecchi, ${ }^{10}$ Alessandro Sanduzzi \\ Zamparelli, ${ }^{11}$ Emma Tedeschini, ${ }^{12}$ Benedetta Biagioni, ${ }^{13}$ Margarita Murrieta-Aguttes, ${ }^{14}$ Maria D'Amato ${ }^{15}$ \\ 'Division of Respiratory and Allergic Diseases, Department of Chest Diseases, High Speciality Hospital 'A. Cardarelli', \\ Naples, Italy; ${ }^{2}$ Medical School of Specialization in Respiratory Diseases, Federico II University of Naples, Italy; \\ ${ }^{3}$ Epidemiology of Allergic and Respiratory Diseases Department, IPLESP, Paris, France; ${ }^{4}$ Research Director Co- \\ Directrice/Deputy Director IDESP, INSERM, University of Montpellier, France; ${ }^{5}$ Department of Pediatrics, Federal \\ University of Pampa, RS, Brazil; ${ }^{6}$ Department of Medical Sciences and Public Health, University of Cagliari, Italy; \\ ${ }^{7}$ Department of Pediatrics, Federal University of Parana, PR, Brazil; ${ }^{8}$ Department of Pediatrics, Federal University of São \\ Paulo, SP, Brazil; ${ }^{9}$ Department of Allergy and Immunology, Hospital Quiron Salud Bizkaia, Bilbao, Spain; ${ }^{10}$ Center of

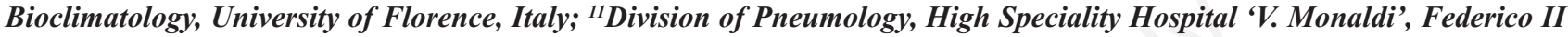 \\ University of Naples Medical School, Naples, Italy; ${ }^{12}$ Department of Agricultural Food and Environmental Science, \\ University of Perugia, Italy; ${ }^{13}$ The Allergy Outpatient Clinic-, Division of Internal Medicine, IRCCS, Azienda Ospedaliera \\ Universitaria, Bologna, Italy; ${ }^{14}$ Specialist in Allergy and Immunology, Paris, France; ${ }^{15}$ First Division of Pneumology, High \\ Speciality Hospital 'V. Monaldi', Federico II University of Naples Medical School, Naples, Italy
}

Thunderstorm-triggered asthma (TA) can be defined as the occurrence of acute asthma attacks immediately following a thunderstorm during pollen seasons. Outbreaks have occurred across the world during pollen season with the capacity to rapidly inundate a health care service, resulting in potentially catastrophic outcomes for allergic patients. TA occurs when specific meteorological and aerobiological factors combine to affect predisposed atopic patients with IgE-mediated sentitization to pollen allergens. Thunderstorm outflows can concentrate aeroallergens, most commonly grass pollen but also other pollens such as Parietaria and moulds in TA, at ground level to release respirable allergenic particles after rupture by osmotic shock related to humidity and rainfall. Inhalation of high concentrations of these aeroallergens by sensitized individuals can induce early asthmatic responses which can be followed by a late inflammatory phase. There is evidence that, during pollen season, thunderstorms can induce allergic asthma outbreaks, sometimes also severe asthma crisis and sometimes deaths in patients suffering from pollen allergy. It has been observed that changes in the weather such as rain or humidity may induce hydratation of pollen grains during pollen seasons and sometimes also their fragmentation which generates atmospheric biological aerosols carrying allergens. Asthma attacks are induced for the high concentration at ground level of pollen grains which may release allergenic particles of respirable size after rupture by osmotic shock. In other words, it is a global health problem observed in several cities and areas of the world that can strike without sufficient warning, inducing sometimes severe clinical consequences also with deaths of asthma patients. Due to constant climate change, future TA events are likely to become more common, more disastrous and more unpredictable, as a consequence it is important to have deep knowledge on this topic to prevent asthma attacks. Other environmental factors, such as rapid changes in temperature and agricultural practices, also contribute to causing TA.

Key words: Thunderstorm-asthma; pollen allergy; mould allergy; allergic rhinitis; allergic asthma; acute asthma attacks; near fatal asthma.

Correspondence: Prof. Gennaro D'Amato, Division of Respiratory and Allergic Diseases, High Speciality Hospital 'A. Cardarelli', Medical School of Specialization in Respiratory Diseases, Federico II University of Naples, Rione Sirignano 10, 80121 Naples, Italy. E-mail: gdamatomail@gmail.com

Contributions: All the authors have contributed equally to the manuscript. All the authors have read and approved the final version of the manuscript.

Conflict of interest: The authors declare no conflict of interest for this work. GDA is a member of the Editorial Board of Multidisciplinary Respiratory Medicine. IAM is an Associate Editor of Multidisciplinary Respiratory Medicine.

Funding: None.

Avaibility of data and materials: Available from the corresponding author upon reasonable request.

Ethics approval and consent to participate: Not applicable.

Consent for publication: Not applicable. 


\section{Introduction}

During the first phase of a thunderstorm patients suffering from pollen allergy may inhale a high concentration of the allergenic material, like biological antigenic aerosols dispersed in atmosphere, which can induce asthmatic reactions also severe in pollinosis patients [1-10]. Even though thunderstorms can induce severe asthma attacks, they are neither frequent nor responsible for high amount of disease exacerbations. Yet, the mechanisms involved in the release of allergens from pollens during thunderstorm and associated risk should be known by physicians, not only allergists but also general practitioner (GP) and pollen allergic patients for a prevention (Figure 1) [11,12]. In addition, there is a potential risk of thunderstorm-related relapse of asthma attacks in some patients [13]. This constitute a huge concern as the possibility of thunderstorm-associated asthma (TA) outbreaks becomes of dramatic actuality nowadays because the frequency of thunderstorms is recently increased significantly in some geographical areas, particularly in temperate and subtropical climate due to the climate change [14].

Over the last few decades, incidences of respiratory admissions have risen due to the increased atmospheric concentration of airborne allergens. The fragmentation and dispersion of these allergens is aided by environmental factors like rainfall, temperature, and interactions with atmospheric aerosols [15]. Extreme weather parameters, which continue to become more frequent due to the impacts of climate change, have greatly fluctuated allergen concentrations and led to epidemic TA events which have left hundreds, if not thousands, struggling to breathe [5,9,16-18]. While a link exists between airborne allergens, weather, and respiratory admissions, the underlying factors that influence these epidemics remain unknown [19]. It is important we understand the potential threat these events pose on our susceptible populations and ensure our health infrastructure is prepared for the next epidemic [20].

After the event of London 1994 [6], the most lethal TA event occurred in Melbourne, Australia, in 2016. Studies on the affected individuals found TA to be associated with allergic rhinitis, ryegrass pollen sensitization, pre-existing asthma, poor adherence to inhaled corticosteroid preventer therapy, hospital admission for asthma in the previous year and outdoor location at the time of the storm. Patients without a prior history of asthma were also affected $[8,10,21,22]$. These factors are important in extending our understanding of the etiology of TA and associated clinical indicators as well as possible biomarkers which may aid in predicting those at risk and thus those who should be targeted in prevention campaigns [23]. Education on the importance of recognizing asthma symptoms, adherence to asthma treatment and controlling seasonal allergic rhinitis is vital in preventing TA. Consideration of allergen immunotherapy in selected patients may also mitigate risk of future TA. Epidemic TA events are predicted to increase in frequency and severity with climate change, and identifying susceptible patients and preventing poor outcomes is a key research and public health policy priority [24].

Associations between thunderstorms and asthma attacks have been identified in multiple locations around the world $[22,25,26]$. The TA outbreaks are characterized, at the beginning of thunderstorms, by a rapid increase of visits for asthma in GP or hospital emergency departments [12,21]. Subjects without asthma symptoms but affected by seasonal rhinitis can experience an asthma attack $[5,9,16]$.

No unusual levels of air pollution were noted at the time of the epidemics, but there was a strong association with high atmospheric concentrations of pollen grains such as grasses or other allergenic plant species. However, subjects affected by pollen allergy should be informed about a possible risk of asthma attack at the beginning of a thunderstorm during pollen season (Tables 1 and 2) [27-31].

Thunderstorm-related asthma outbreaks have been described in various geographical zones (Table 3)

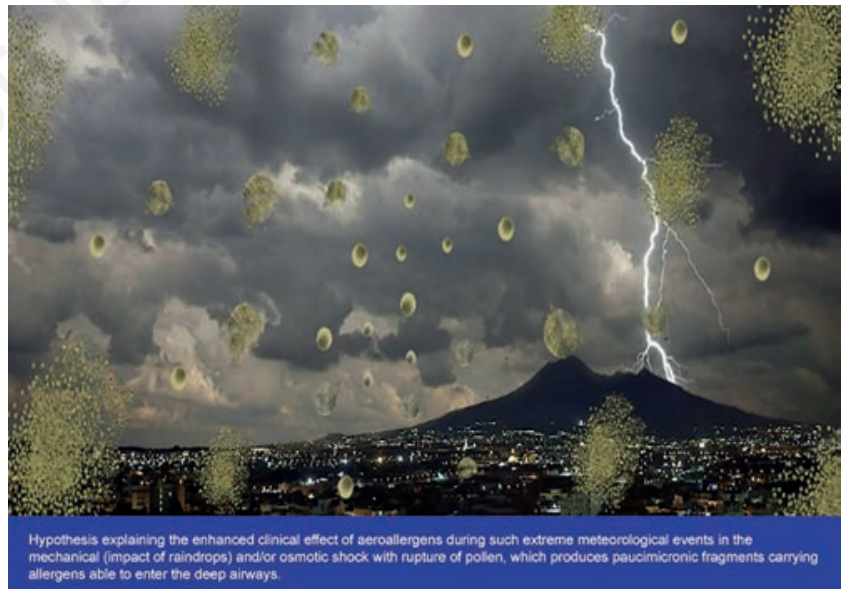

Figure 1. Rupture of pollen during a thunderstorm.

\section{Table 1. Thunderstorm asthma.}

- Thunderstorm asthma is a form of asthma that is triggered by an uncommon combination of high pollen (usually during late spring to early summer) and a certain kind of thunderstorm.

- Anyone can be affected, even if you do not have a history of asthma.

- People at increased risk have a history of asthma, have unrecognised asthma, have hay fever (allergic rhinitis), (particularly seasonal hay fever), or are allergic to grass pollen.

- People experiencing asthma symptoms even if for the first time should not ignore it, and should seek medical advice as soon as possible.

- An asthma flare up can vary in severity and can be life-threatening. If there are signs that a person's condition is deteriorating, urgent care should be sought.

- Be aware of forecast thunderstorms in the pollen season particularly on days with a HIGH or EXTREME pollen count. Where possible, stay indoors with doors and windows closed until the storm front has passed. 


\section{Who is at risk of thunderstorm asthma?}

TA can affect people living in metropolitan, regional or rural areas. it can affect people who have never been diagnosed with asthma. Those at increased risk of thunderstorm asthma include people with a history of asthma, people with undiagnosed asthma and people with hay fever (particularly seasonal hay fever) or allergy to grass pollen [32].

On 21 november 2016 in Melbourne there was a dramatic event with 10 deaths and about 10,000 patients who needed medical treatments in Emergency Departments of the hospitals for asthma attacks $[1,2,4,21,22]$. This in Melbourne has been the worst event of TA. In Melbourne there was an extraordinary association of environmental factors with a very unusual weather occurrence with wind and torrential rain combined with a high pollen count (grass pollen airborne count of more than 100 pollens for cubic meter), sending high quantity of pollens and allergenic submicronic particles derived from pollens across the city. Asthma epidemics with thunderstorms are an increasingly significant public health challenge worldwide. Australia has experienced 10 of 22 TA epidemics recorded so far, the most recent in Melbourne in 2016. In just 12 hours, a single storm put unprecedented pressure on available health resources, resulting in the death of ten patients and 10,000 cases related to asthma in health services $[1,2,21,22]$. The challenge faced by emergency response services indicates that it is

Table 2. Aspects of epidemics of thunderstorm-associated allergic asthma in the world.

- There is a link between storms and asthma epidemics in patients with pollen allergy during pollen seasons with appearence of symptoms during the first 20-30 minutes of a storm.

- $\quad$ Thunderstorm-related epidemics are limited to late spring and summer (in Europe, USA and Canada from April to end of June and in Australia from October to December), when pollen and/or mold counts are high.

- There are no descriptions of allergic symptoms in individuals with allergy to pollens and molds but who are indoors with the window closed during a storm.

- It is possible the role of sudden cold and/or electric charges as contributor trigger factors of asthma attack in allergic subjects.

- Individuals with allergic rhinitis only and no previous asthma can experience bronchoconstriction sometimes also severe during thunderstorms.

- Subjects with pollen allergy need be informed about a possible risk of asthma attack at the beginning of a thunderstorm during pollen season.

- Individuals who experience rhinitis and asthma during a storm are not usually taking suitable anti-inflammatory treatment, while it is important to have a correct antiasthma treatment by using bronchodilators and corticosteroids by inhalation at increasing dosage if there is a need (https:/ginasthma.org/gina-reports/)

- The world's worst recorded thunderstorm asthma attack was on $21^{\text {st }}$ November 2016 in Melbourne, where nine subjects died and more than 8,500 were hospitalised in Victoria. It caused many people, including those who had no history of asthma or respiratory issues, to experience mild to severe breathing difficulties and near fatal asthma.

- Any serious asthma attack during a thunderstorm can be life-threatening and can induce also tragic consequences of near fatal asthma and of death.

- The health consequences of thunderstorm asthma may be prevented with adequate measures by meteorological forecast and by correct use of patients of adequate antiallergic and antiasthma therapy and avoiding to be outdoors at the start of a storm during pollen season.

Table 3. Examples of thunderstorm-associated asthma outbreaks.

\begin{tabular}{|c|c|c|}
\hline Year & Country & Observations \\
\hline 1983 & UK & Twenty-six sudden cases of asthma attacks in relation to thunderstorms. \\
\hline 1992 & Australia & Late spring thunderstorms in Melbourne can trigger epidemics of asthma attacks (five to 10-fold rise). \\
\hline 1997 & UK & $\begin{array}{l}\text { Asthma or other airways disease hospital visits; } 640 \text { cases attending during a } 30 \text {-h period on June 1994, nearly } 10 \text { times more } \\
\text { than expected. }\end{array}$ \\
\hline $1992-2000$ & Canada & $\begin{array}{l}\text { Hospital ED asthma visits among children } 2-15 \text { years of age. Summer thunderstorm activity was associated with an OR of } 1.35 \\
\text { ( } 95 \% \text { CI 1.02-1.77) relative to summer periods with no activity. }\end{array}$ \\
\hline $1993-2004$ & USA & $\begin{array}{l}\text { Asthma ED visits; the visits occurred on days following thunderstorms. Significant association between daily counts of asthma ED } \\
\text { visits and thunderstorm occurrence. Asthma visits were } 3 \% \text { higher on days following thunderstorms. }\end{array}$ \\
\hline 2000 & Australia & $\begin{array}{l}\text { Asthma visits during thunderstorms. History of hay fever and allergy to ryegrass are strong predictors for asthma exacerbation } \\
\text { during thunderstorms in spring. }\end{array}$ \\
\hline 2001 & Australia & $\begin{array}{l}\text { The incidence of excess hospital attendances for asthma during late spring and summer was strongly linked to the occurrence } \\
\text { of thunderstorm outflows }\end{array}$ \\
\hline 2002 & UK & $\begin{array}{l}\text { A case-control study of } 26 \text { patients presenting to Cambridge University Hospital with asthma after the thunderstorm Alternaria } \\
\text { alternate sensitivity is a compelling predictor of epidemic asthma in patients with seasonal asthma and grass pollen allergy and is } \\
\text { likely to be the important factor in thunderstorm-related asthma. }\end{array}$ \\
\hline 2004 & Italy & Six cases of thunderstorm-related asthma because of pollen (Parietaria). \\
\hline 2010 & Italy & Twenty cases of thunderstorm-related asthma because of pollen (olive tree). \\
\hline 2010 & Australia & $\begin{array}{l}\text { Epidemics of 'thunderstorm asthma' that occurred in Melbourne during spring 2010. The approach of spring, together with high } \\
\text { winter rainfall in and around Melbourne that heralds another severe pollen season, raises the risk of allergic rhinitis and asthma } \\
\text { in pollen-sensitive individuals. }\end{array}$ \\
\hline 2016 & Australia & pidemics of thunderstorm asthma in Melbourne with 10 deaths and 9,000 in emergency department. \\
\hline
\end{tabular}


time to examine the role of all emergency healthcare providers in providing the solutions needed to manage outbreak events of this type [33]. It is an important alert for physicians, paramedics and emergency facilities to be prepared to respond to any large-scale storm asthma event in the future [12].

During TA epidemics, GPs experience an increase in demand for services, although GPs express willingness to help, few structures exist to liaise, support and provide information to GPs during emergency events [20]. In Melbourne, ambulances and hospitals experienced a huge involvement in a reduced time period of a few hours on 21 November, with grass allergens dispersed over a very large geographical area of Victoria. The rapid onset of the medical emergency and its consequences were unprecedented in the scale of the intensity in comparison with previous events and it tested the capacity of health system to be ready for this type of medical emergency [7]. However, demand management strategies were insufficient to manage such a widespread and rapid onset event, with ambulance resources quickly depleted and using police officers to conduct welfare cheks [8]. The event of Melbourne greatly surpassed the previous epidemic of London in June 1994 [28,34] that was the largest documented outbreak before the Victoria epidemic.

Thunderstorms have been linked to asthma epidemics, especially during the pollen seasons, and there are descriptions of asthma outbreaks associated with thunderstorms, which occurred in several cities, prevalently in Europe (Birmingham and London in the UK [6] and Naples in Italy $[1,2]$ ) and Australia (Melbourne and Wagga Wagga) [3,4-7]. There are observations that thunderstorms occurring during pollen season can induce asthma attacks sometimes severe and near fatal asthma in pollinosis patients $[1,25,35]$.

According to current climate change scenarios, there will be an increase in intensity and frequency of heavy rainfall episodes, including thunderstorms, over the next few decades, which can be expected to be associated with an increase in the number and severity of asthma attacks both in adults and in children $[1,2,26,36]$. One of the first observations regarding thunderstorms and asthma outbreaks was provided by Packe and Ayres [37] at the East Birmingham Hospital (Birmingham, UK) on July 6 and 7, 1983. These authors described a remarkable increase in the number of asthma emergency department admissions during the hours of a thunderstorm. In a 36-h period, 26 asthma cases were treated in the emergency department, compared with a daily average of two or three cases in the days preceding the outbreak.

Another asthma outbreak occurred in London, UK, coinciding with a heavy thunderstorm on June 24, 1994, when a large increase in the number of visits for asthma at the emergency departments of London and the Southwest of England was observed. Several patients who were examined, who were not known to be asthmatics or were affected only by seasonal rhinitis, experienced an asthma attack. During a 30-h period from 6 p.m. on June 24, 1994, 640 patients with asthma or other airways disease (283 of whom were not known to be asthmatic and 403 were affected only by seasonal rhinitis) attended several emergency departments, nearly 10 times the expected number of 66 patients. In total, 104 patients were admitted (including five to an intensive care unit) (574 patients attributable to the thunderstorm) [28].

Other asthma outbreaks during thunderstorms have been described in Australia. In Melbourne, other than the dramatic outbreak of 21 November 2016, two large asthma outbreaks (rapid increase in hospital or general practitioner visits for asthma) coincided with thunderstorms. In Wagga Wagga, 215 asthmatic subjects attended the local Emergency Department, 41 of whom required admission to hospital [38]. In South Eastern Australia [38] also before the event of 2016, it was observed that the incidence of excess hospital attendances for asthma during late spring and summer was strongly linked to the occurrence of thunderstorm out- flows and demonstrated that the arrival of a thunderstorm outflow was accompanied by a large increase in the concentration of ruptured pollen grains in ambient air.

TA was observed in Naples, Italy, on $3^{\text {rd }}$ June 2004 [1,2], when five adults and one child received treatment in emergency departments. One patient was admitted to an intensive care unit for a very severe bronchial obstruction and acute respiratory insufficiency following a sudden thunderstorm. All individuals were outdoors when the thunderstorm struck. In one severe case, a female sensitized to Parietaria pollen allergen only, soon began to show symptoms of intense dyspnoea, which gradually worsened. She was taken to hospital where she was intubated and given high intravenous doses of corticosteroids. She was discharged a few days later [2]. This patient had previously suffered from seasonal asthma but had been asthma-free for the past few years and did not need continuous therapy. None of the other five subjects took antiallergic and/or anti-asthma drugs regularly. All six patients were sensitized with allergic respiratory symptoms upon exposure to Parietaria pollen but were not sensitized to grasses. Parietaria is an Urticacea that is widespread in the Naples area of Italy with a spring and summer pollen season that is, in part, coexistent with that of grasses. During the thunderstorm, the concentration of airborne Parietaria pollen grains was particularly high, with a peak of 144 grains $/ \mathrm{m}^{3}$ being recorded on June 3, 2004. Air pollution levels for both gaseous and particulate components based on the hourly concentrations of nitric dioxide, ozone and respirable particulate matter were not particularly high in Naples on June 3 and 4, 2004. Subjects with sensitization to Parietaria who were indoors in Naples with the windows closed during the night between June $3^{\text {rd }}$ and $4^{\text {th }}, 2004$, did not experience asthma attacks. No moulds or viruses were involved in the Naples' epidemics $[1,2]$.

Other outbreaks and/or case reports have been described in Barletta (Italy) [27], in Atlanta (USA) [39], in Canada [25] and in several other cities in the world. A similar phenomenon has been suggested for moulds after the observation of a possible key role of sensitization to Alternaria species in TA [40]. A similar phenomenon has been suggested for moulds after the observation of a possible key role of sensitization to Alternaria species in thunderstormrelated asthma [40]. Although much remains to be discovered about the relationship between an increase in the number of asthma attacks and thunderstorms, reasonable evidence exists in favour of a causal link between them in patients suffering from pollen allergy.

The most prominent hypotheses for TA are linked with bioaerosols, and involve the role of rainwater in promoting the release of respirable particulate matter [15]. Pollen grains can be carried by thunderstorm at ground level, where pollen rupture would be increased with release of allergenic biological aerosols of paucimicronic size, derived from the cytoplasm and which can penetrate deep into lower airways. In other words, there is evidence that under wet conditions or during thunderstorms, pollen grains may, after rupture by osmotic shock, release into the atmosphere part of their content, including respirable, allergen-carrying cytoplasmic starch granules $(0.5-2.5 \mu \mathrm{m})$ or other paucimicronic components that can reach lower airways inducing asthma reactions in pollinosis patients $[15,17]$. These allergens can likely penetrate deeper into the lung, provoking more severe symptoms. It has been suggested that grass pollen starch granules are the most likely cause of associations between thunderstorms and asthma. Suphioglu et al. [29] showed that ryegrass pollen grains contain a large amount of starch granules coated with allergens. After being ruptured in rainwater by osmotic shock, each grain can release 700 starch granules, which are small enough to penetrate the airways and trigger asthma attacks in previously sensitized subjects. Taylor et al. [42] hypothesized that the turbulent front of the advancing 
outflow releases more pollen from flowering grasses and grass pollen may release large amounts of paucimicronic allergenic particles, that is cytoplasmatic starch granules containing grass allergens (allergenbearing starch granules), after rupture by osmotic shock during thunderstorms.

Even though thunderstorms can induce severe asthma attacks or exacerbations, they are neither frequent nor responsible for a high amount of disease exacerbation. This constitutes a major concern nowadays as the possibility of TA outbreaks have become of dramatic actuality due to the "highly likely" increase in frequency of heavy precipitation events, including thunderstorms, projected by the climate change scenarios for the future decades. In summary, the occurrence of these epidemics is closely linked to thunderstorm and they are limited to late spring and summer when there are high levels of airborne pollen grains. There is a close temporal association between the arrival of the thunderstorm, a major rise in the concentration of pollen grains and the onset of epidemics. As a consequence, subjects affected by pollen allergy should be alert to the danger of being outdoors during a thunderstorm in the pollen season $[41,42]$.

Idrose et al. [43] in a recent systematic review evaluated the associations of grass pollen and fungi in TA events, noting that out of 20 studies included in the analysis, 15 showed some relationship, nine demonstrated effects within four days of increased pollen concentration associated with increased risk of stormy asthma. Out of the 10 studies that looked at fungi, nine showed a positive relationship with storm asthma. The rates of fungi involved varied depending on whether measurements were taken before, during or after the storm. Xu et al. [26] reported in the city of Yulin (China) that children with mugwort allergy are susceptible to stormy asthma, noting a preponderance of males. Among children hospitalized during the event, $56 \%$ of them never had attacks or were diagnosed with asthma, $25 \%$ had a medical diagnosis of asthma, $67 \%$ had a history of allergic rhinitis, $76 \%$ moderate asthma, $94 \%$ had positive IgE against mugwort pollen and $78 \%$ were monosensitized to pollen. Identifying at-risk individuals is the most prophylactic approach that can be taken to mitigate the deadly consequences of TA [14]. The main risk factor appears to be a history of allergic rhinitis or sensitization to a particular allergen, circulating load of triggering aeroallergens, and age between 20-50 years. People exposed to the external environment are also more likely to suffer from stormy asthma and men are more likely to be affected than women [32]. Elderly people or those with common chronic respiratory diseases, such as asthma or chronic obstructive pulmonary disease (COPD), are more susceptible to negative health effects resulting from these phenomena. Zou et al. [36] report that emergency visits for acute respiratory illnesses increased significantly during the days before major storms among medicare beneficiaries across the continental United States, particularly those with asthma and/or COPD. These findings suggest that past increases in particulate matter concentration and temperature may be the dominant mechanism of storm-associated acute respiratory illness in older Americans, which may contribute to a burden on the health care system as storm activity increases with storm, increase in global temperatures [36]. Thunderstorm was considered unlikely to occur in New Zealand due to its local weather patterns, but events on $2^{\text {nd }}$ December 2017 led to an increase in asthma hospitalizations at Waikato Hospital in Hamilton, with similar presentations to international descriptions of asthma by storm [44]. Ali et al. [35] reported cases of near-fatal and fatal asthma caused by storms in Kuwait on December $1^{\text {st }}$, 2016; 17 patients were admitted with near-fatal asthma, 93.8\% had a previous history of asthma, with an average duration of 9 years, $33.3 \%$ reported receiving inhaled corticosteroids from their physician and $93.8 \%$ relying only on a short-acting $\beta 2$-agonist to control their asthma; $68.8 \%$ reported being outdoors during the storm and eleven patients were diagnosed with fatal asthma. Foo et al. [45] reported, in individuals affected by TA, evidence of continuous loss of asthma control in those with previously well-controlled asthma and persistence of symptoms suggestive of asthma in those without a history or symptoms suggestive of previous asthma, even after 36 months of initial TA. Suboptimal rates of adherence to inhaled preventive and having an asthma action plan may contribute to the risk of asthma exacerbation and susceptibility to future episodes of AT. Long-term follow up is required to determine the extent and severity of this apparent change [45]. Hew et al. [21] reported about patients with asthma caused by epidemic storms who presented to the emergency room, greater chances of hospitalization among patients with diagnosed asthma, highlighting the vulnerability conferred by the suboptimal control of the disease. The odds of hospital admission were lower in overseasborn Asian patients, but higher in locally-born Asian patients than in non-Asian patients; these observations suggest that susceptibility to severe asthma from storms may be increased by gene-environment interactions.

Family and Community Medicine is the main point of access to medical care for many patients during disasters and sudden events. Emergency planners should not assume that most disaster victims require hospitalization or even emergency department evaluation. Screening and treatment can be carried out effectively in services attended by GP, thus avoiding the overload of hospital facilities when a large number of patients seek medical care at once, but little is known about how to properly integrate the response of the general practice to general emergency care response $[12,20,33]$.

\section{References}

1. D'Amato G, Annesi Maesano I, Molino A, Vitale C, D'Amato M. Thunderstorm-related asthma attacks. J Allergy Clin Immunol 2017;139:1786-87.

2. D'Amato G, Vitale C, D'Amato M, Cecchi L, Liccardi G, Molino A, et al Thunderstorm-related asthma: what happens and why. Clin Exp Allergy 2016;46:390-6.

3. Andrew E, Nehme Z, Bernard S, Abramson MJ, Newbigin E, Piper B, et al. Stormy weather: a retrospective analysis of demand for emergency medical services during epidemic thunderstorm asthma. BMJ 2017;359:j5636.

4. D'Amato G, Annesi-Maesano I, Vaghi A, Cecchi L, D'Amato M. how do storms affect asthma? Curr Allergy Asthma Rep 2018;18:24.

5. D'Amato G, Akdis C. Global warming, climate change, air pollution and allergies. Allergy 2020;75:2158-60.

6. Davidson AC, Emberlin J, Cook AD, Venables KM. Thames region accident and emergency traineer association. A major outbreak of asthma associated with a thunderstorm. BMJ 1996;312:601-4.

7. Lindstrom SJ, Silver JD, Sutherland MF. Thunderstorm asthma outbreak of November 2016: a natural disaster requiring planning. Med J Aust 2017;207:235-7.

8. Lee J, Kronborg C, O'Hehir RE, Hew M. Who's at risk of thunderstorm asthma? The ryegrass pollen trifecta and lessons learnt from the Melbourne thunderstorm epidemic. Respir Med 2017;132:146-8.

9. D'Amato G, Holgate ST, Pawankar R, Ledford DK, Cecchi L, Al-Ahmad M, et al Meteorological conditions, climate change, new emerging factors and asthma and related allergic disorders. A statement of the World Allergy Organization. World Allergy Organ J 2015;8:25. 
10. Bellomo R, Gigliotti P, Treloar A, Holmes P, Suphioglu C, Singh MB et al. Two consecutive thunderstorm associated epidemic of asthma in Melbourne. Med J Aust 1992;156:834-7.

11. Cecchi L, D'Amato G, Annesi-Maesano I. Climate change and outdoor aeroallergens related to allergy and asthma: Taking the exposome into account. Allergy 2020;75:2361-3.

12. D'Amato G, Rottem M, Dahl R, Blaiss M, Ridolo E, Cecchi L, et al. Climate change, migration and allergic respiratory diseases: an update for the allergist. World Allergy Organ J 2011;4:120-5.

13. Farouque AS, Walker R, Erbas B. Thunderstorm asthma epidemic - A systematic review of the general practice perspective. Int J Environ Res Public Health 2020;17:3796.

14. Foo CT, Fernando S, Cohen N, Adabi G, Lim CMT, Young AC, et al. Natural history of asthma symptoms after epidemic thunderstorm asthma: a 3-year longitudinal study. Asia Pac Allergy 2020;21;10:e30.

15. Price D, Hughes KM, Thien F, Suphioglu C. Thunderstorm asthma: Lessons learned from the storm down-under. J Allergy Clin Immunol Pract 2021;9:1510-5.

16. D'Amato G. Airborne paucimicronic allergen-carrying particles and seasonal respiratory allergy. Allergy 2001;56:1109-11.

17. D'Amato G, Vitale C, Lanza M, Molino A, D'Amato M. Climate change, air pollution and allergic respiratory diseases: an update. Curr Opin Allergy Clin Immunol 2016;16:434-40.

18. D'Amato G. Environmental urban factors (air pollution and allergens) and the rising trends in allergic respiratory diseases. Allergy 2002;57:s30-3.

19. D'Amato M, Cecchi L, Annesi-Maesano I, D'Amato G. News on climate change, air pollution and allergic trigger factors of asthma. J Investig Allergol Clin Immunol 2018;28:91-7.

20. Harun NS, Lachapelle P, Douglass J. Thunderstorm-triggered asthma: what we know so far. J Asthma Allergy 2019;12:1018.

21. Farouque AS, Walker R, Erbas B. Thunderstorm asthma epidemic - management challenges experienced by general practice clinics. J Asthma 2021;58:423-9.

22. Hew M, Lee J, Susanto NH, Prasad S, Bardin PG, Barnes S, et al. The 2016 Melbourne thunderstorm asthma epidemic: Risk factors for severe attacks requiring hospital admission. Allergy 2019;74:122-30.

23. Thien F, Beggs PJ, Csutoros D, Darvall J, Hew M, Davies JM, et al. The Melbourne epidemic thunderstorm asthma event 2016: An investigation of environmental triggers, effect on health services, and patient risk factors. Lancet Planet Health 2018;2:e255-63.

24. Marks GB, Bush RK. It's blowing in the wind: new insights into thunderstorm-related asthma. J Allergy Clin Immunol 2007; 120:530-2.

25. Celenza A, Fothergill J, Kupek E, Shaw RJ. Thunderstorm associated asthma: a detailed analysis of environmental factors. BMJ 1996;312:604-7.

26. Wardman AE, Stefani D, MacDonald JC. Thunderstorm-associated asthma or shortness of breath epidemic: a Canadian case report. Can Respir J 2002;9:267-70.
27. Xu YY, Xue T, Li HR, Guan K. Retrospective analysis of epidemic thunderstorm asthma in children in Yulin, northwest China. Pediatr Res 2021;89:958-91.

28. Losappio L, Heffler E, Contento F, Cannito C, Rolla G. Thunderstorm related asthma epidemic owing to Olea Europaea pollen sensitization. Allergy 2011;66:1510-1.

29. Newson R, Strachan D, Archibald E, Emberlin J, Hardaker P, Collier C. Acute asthma epidemics, weather and pollen in England, 1987-1994. Eur Resp J 1998;11:694-701.

30. Suphioglu C, Singh MB, Taylor P, Knox RB, Bellomo R, Holmes $\mathrm{P}$, et al. Mechanism of grass-grass-pollen induced asthma. Lancet 1992;339:569-72.

31. Knox RB. Grass pollen, thunderstorms and asthma. Clin Exp Allergy 1993;23:354-6.

32. Traidl-Hoffmann C, Kasche A, Menzel A, Jakob T, Thiel M, Ring J, et al. Impact of pollen on human health: more than allergen carriers? Int Arch Allergy Immunol 2003;131:1-13.

33. Kevat A. Thunderstorm asthma: Looking back and looking forward. J Asthma Allergy 2020;8;13:293-9.

34. Redwood-Campbell L, Abrahams J. Primary health care and disasters - The current state of the literature: What we know, gaps and next steps. Prehospital Disaster Med 2011;26:18491.

35. Ali F, Behbehani N, Alomair N, Taher A. Fatal and near-fatal thunderstorm asthma epidemic in a desert country. Ann Thorac Med 2019;14:155-60.

36. Zou E, Worsham C, Miller NH, Molitor D, Reif J, Jena AB. Emergency visits for thunderstorm-related respiratory illnesses among older adults. JAMA Intern Med 2020;180:1248-50.

37. Packe GE, Aires JG. Asthma outbreak during a thunderstorm. Lancet 1985;2:199-204.

38. Girgis ST, Marks GB, Downs SH, Kolbe A, Car GN, Paton R. Thunderstorm associated asthma in an inland town in southeastern Australia. Who is at risk? Eur Resp J 2000;16:3-8.

39. Grundstein A, Sarnat SE, Klein M, Shepherd M, Naeher L, Mote T, Tolbert P.Thunderstorm associated asthma in Atlanta Georgia. Thorax 2008;63:659-60.

40. Pulimood TB, Corden JM, Bryden C, Sharples L, Nasser SM. Epidemic asthma and the role of the fungal mould Alternaria alternata. J Allergy Clin Immunol 2007;120:610-7.

41. D'Amato G, Cecchi L, Annesi-Maesano I. A trans-disciplinary overview of case reports of thunderstorm-related asthma outbreak and relapse. Eur Respir Rev 2012;21:82-7.

42. Taylor PE Flagan R, Valenta R, Glovsky MM. Release of allergens in respirable aerosol: a link between grass pollen and asthma. J Allergy Clin Immunol 2002;109;51-6.

43. Idrose NS, Dharmage SC, Lowe AJ, Lambert KA, Lodge CJ, Abramson MJ, et al. A systematic review of the role of grass pollen and fungi in thunderstorm asthma. Environ Res 2020;181:108911.

44. Sabih A, Russell C, Chang CL. Thunderstorm-related asthma can occur in New Zealand. Respirol Case Rep 2020;8:e00655.

45. Foo CT, Yee EL, Young A, Denton E, Hew M, O'Hehir RE, et al. Continued loss of asthma control following epidemic thunderstorm asthma. Asia Pac Allergy 2019;17;9:e35.

Received for publication: 13 September 2021. Accepted for publication: 14 October 2021.

This work is licensed under a Creative Commons Attribution-NonCommercial 4.0 International License (CC BY-NC 4.0).

CCopyright: the Author(s), 2021

Licensee PAGEPress, Italy

Multidisciplinary Respiratory Medicine 2021; 16:806

doi:10.4081/mrm.2021.806 